Article type $\quad: 1$ Original Article - UK, Europe

\title{
The association between subclinical thyroid dysfunction and dementia: the Health, Aging and Body Composition (Health ABC)
}

\section{Study}

Short title: Subclinical thyroid dysfunction and dementia.

Carole E Aubert, MD ${ }^{1}$, Douglas C Bauer, MD ${ }^{2}$, Bruno R da Costa, PhD ${ }^{3}$, Martin Feller, MD, MSc ${ }^{1,3}$, Carole Rieben, MD ${ }^{4}$, Eleanor M. Simonsick, PhD ${ }^{5}$, Kristine Yaffe, MD ${ }^{6,7}$, Nicolas Rodondi, MD, MAS ${ }^{1,3}$.

\section{Authors affiliations:}

${ }^{1}$ Department of General Internal Medicine, Inselspital, Bern University Hospital, University of Bern, Switzerland; ${ }^{2}$ Departments of Medicine and Epidemiology \& Biostatistics, University of California, San Francisco, United States; ${ }^{3}$ Institute of Primary Health Care (BIHAM), University of Bern, Switzerland; ${ }^{4}$ Department of Diabetes, Endocrinology, Clinical Nutrition and Metabolism, Inselspital, Bern University Hospital, University of Bern, Switzerland; ${ }^{5}$ Intramural Research Program, National Institute on Aging, Baltimore, Maryland; ${ }^{6}$ Departments of Psychiatry, and Neurology, University of California, San Francisco; ${ }^{7}$ Department of Epidemiology and Biostatistics, University of California, San Francisco. For the Health ABC Study. This work was conducted at Bern University Hospital, University of Bern, Switzerland.

Correspondence: Carole E Aubert, Department of General Internal Medicine, Inselspital, Bern University Hospital, University of Bern, 3010 Bern, Switzerland; email: caroleelodie.aubert@insel.ch; Phone +41 3163221 11; Fax +41 316328885

Article Category: Original Article.

Keywords: Dementia, Cognitive decline, Cognitive aging, Thyroid dysfunction

This article has been accepted for publication and undergone full peer review but has not been through the copyediting, typesetting, pagination and proofreading process, which may lead to differences between this version and the Version of Record. Please cite this article as doi: 10.1111/cen.13458

This article is protected by copyright. All rights reserved. 
Acknowledgments: The authors have no conflict of interest to disclose. This study was supported by a grant from the Swiss National Science Foundation (SNSF 320030150025 and 320030-172676 to Prof Rodondi). The Health ABC Study was supported by National Institute on Aging (NIA) contracts N01-AG-6-2101; N01-AG-6-2103; N01-AG-6-2106; NIA grant R01-AG028050, and NINR grant R01-NR012459. This research was funded in part by the Intramural Research Program at the National Institute on Aging. We thank Kali Tal for her editorial contributions.

\section{ABSTRACT}

\section{Objective}

Data on the association between subclinical thyroid dysfunction and dementia are limited and conflicting. We aimed to determine whether subclinical thyroid dysfunction was associated with dementia and cognitive decline.

\section{Design}

Population-based prospective cohort study.

\section{Patients}

Adults aged 70-79 years with measured thyroid function, but no dementia at baseline, and Modified Mini-Mental State (3MS) at baseline and follow-up.

\section{Measurements}

Primary outcome was incident adjudicated dementia, based on 3MS, hospital records, and dementia drugs. Secondary outcome was change in 3MS. Models were adjusted for age, sex, race, education, and baseline 3MS, and then further for cardiovascular risk factors.

\section{Results}

Among 2558 adults, $85 \%$ were euthyroid (TSH $0.45-4.49 \mathrm{mIU} / \mathrm{L}$ ), $2 \%$ had subclinical hyperthyroidism with mildly decreased TSH (TSH $0.10-0.44 \mathrm{mIU} / \mathrm{L}), 1 \%$ subclinical hyperthyroidism with suppressed TSH $(\mathrm{TSH}<0.10 \mathrm{mIU} / \mathrm{L}$ with normal free thyroxine [FT4]) and 12\% subclinical hypothyroidism (TSH 4.50-19.99mIU/L with normal

FT4). Over 9 years, 22\% developed dementia. Compared to euthyroidism, risk of dementia was higher in participants with subclinical hyperthyroidisim with suppressed This article is protected by copyright. All rights reserved. 
TSH (HR 2.38, 95\%CI=1.13;5.04), while we found no significant association in those with mildly decreased TSH (HR $0.79,95 \% \mathrm{CI}=0.45 ; 1.38)$ or with subclinical hypothyroidism (HR 0.91, 95\% CI=0.70;1.19). Participants with subclinical hyperthyroidism with suppressed TSH had a larger decline in 3MS $(-3.89,95 \% \mathrm{CI}=-$

\subsection{2;-0.15). Conclusions}

Among older adults, subclinical hyperthyroidism with a $\mathrm{TSH}<0.10 \mathrm{mIU} / \mathrm{L}$ was associated with a higher risk of dementia and a larger cognitive decline, while subclinical hyperthyroidism with mildly decreased TSH or subclinical hypothyroidism were not.

\section{INTRODUCTION}

Subclinical thyroid dysfunction (SCTD), defined as abnormal TSH with normal free thyroxine (FT4), is strongly associated with age, with a prevalence of $4.5 \%$ for subclinical hyperthyroidism (SHyper) and $20 \%$ for subclinical hypothyroidism (SHypo) in the over-60 population. ${ }^{1-3}$ Similarly, dementia is common with aging, reaching a prevalence of $7-10 \%$ after 60 years. ${ }^{4}$

Cognitive impairment is associated with overt thyroid dysfunction, ${ }^{5,6}$ but data on SCTD are limited and conflicting. SHyper was associated with cognitive impairment or dementia in one retrospective ${ }^{7}$ and two cross-sectional studies. ${ }^{8,9}$ Our recent metaanalysis of prospective cohorts found SHyper, but not SHypo, was associated with dementia, while decline in Mini-Mental State Examination (MMSE) was similar in both conditions, when compared with euthyroidism. ${ }^{10}$ However, most studies presented limitations: short time of follow-up, no dementia adjudication, incomplete assessment of potential confounding variables. ${ }^{10}$ Additionally, study-level metaanalyses of observational studies are subject to potential bias (ecological fallacy), and do not allow reliable subgroup analyses, e.g. stratified by sex. ${ }^{11}$ 
If SCTD is associated with a higher risk of dementia, the mechanisms may be complex and at least partially depend on the relationship of SCTD with cardiovascular risk factors. ${ }^{12}$ SCTD is indeed associated with coronary heart disease and arterial stiffness, with the latter a probable risk factor for vascular dementia. ${ }^{12,13}$

We examined in a large prospective cohort study of older adults with a long follow-up time and high-quality data, the association of SCTD with dementia and cognitive decline, and the potential role of cardiovascular risk factors in this relationship.

\section{MATERIAL AND METHODS}

Reporting is in accordance with the STrengthening the Reporting of OBservational studies in Epidemiology (STROBE) statement. ${ }^{14}$

\section{Study population}

Participants were part of the Health, Aging and Body Composition (Health ABC) study, a prospective cohort study of 3075 community-dwelling adults, aged 70-79 years at enrollment (1997-1998) and followed over ten years. Participants were recruited from a random sample of white Medicare beneficiaries and all black people living in designated zip code areas in and around Memphis (Tennessee) or Pittsburgh (Pennsylvania). Race was assessed because of potential differences in health outcomes. The study excluded participants with dementia, who had difficulty with activities of daily living, could not walk a quarter of a mile, could not climb 10 steps without resting, had life-threatening cancer, or planned to move out of the area in the next three years. The Health ABC Study was approved by the institutional review boards of the clinical sites (University of Tennessee, Memphis, and University of Pittsburgh) and the coordinating center (University of California, San Francisco). All participants gave written informed consent. For this analysis, we included participants with cognition assessed by Modified Mini-Mental State (3MS) at Year 1 visit (baseline visit of Health $\mathrm{ABC}$ ) and at least at one follow-up visit, and with measured 
TSH but no dementia at Year 2, leading to a sample of 2601 participants out of 3075 Health ABC participants. We excluded 25 of them for primary hypothyroidism, one for overt secondary hypothyroidism, six for overt primary hyperthyroidism, two for receiving anti-thyroid drugs at Year 2, eight for receiving amiodarone at Year 2, and one for dementia at Year 2, leaving 2558 participants in the analysis. Because of 3MS examination at Year 1 and TSH measurement at Year 2, we did a sensitivity analysis excluding participants with a difference in $3 \mathrm{MS}$ of $>5$ points between Year 1 and Year 3.

\section{Measurements}

\section{Thyroid function}

TSH and FT4 were measured at Year 2 visit in a central laboratory at the University of Vermont, by immunoassay for TSH and by competitive immunoassay for FT4 (ACS; Chiron Diagnostics Corp, Emeryville, Calif). The coefficient of variation for TSH was $4.71 \%$ at $0.30 \mathrm{mIU} / \mathrm{L}$, and $3.64 \%$ at $15.85 \mathrm{mIU} / \mathrm{L}$, according to the manufacturer. Normal range for FT4 with this assay is $10.3-23.2 \mathrm{pmol} / \mathrm{L}(0.8-1.8 \mathrm{ng} / \mathrm{dL})$. In the Health ABC Study, FT4 was measured only if TSH was $<0.1$ or $>7.0 \mathrm{mIU} / \mathrm{L} .{ }^{15}$ Categories of thyroid function were defined as: euthyroidism (TSH=0.45-4.49mIU/L), SHyper (TSH $<0.45 \mathrm{mIU} / \mathrm{L}$ with FT4 within the normal range when TSH $<0.1 \mathrm{mIU} / \mathrm{L}$ ), SHypo (TSH=4.50-19.99mIU/L with FT4 within the normal range when TSH>7.0mIU/L), primary overt hyperthyroidism $(\mathrm{TSH}<0.45 \mathrm{mIU} / \mathrm{L}$ with $\mathrm{FT} 4>23.2 \mathrm{pmol} / \mathrm{L})$, secondary overt hyperthyroidism ( $\mathrm{TSH} \geq 4.50 \mathrm{mIU} / \mathrm{L}$ with $\mathrm{FT} 4>23.2 \mathrm{pmol} / \mathrm{L})$, primary overt hypothyroidism $(\mathrm{TSH} \geq 4.50 \mathrm{mIU} / \mathrm{L}$ with $\mathrm{FT} 4<10.3 \mathrm{pmol} / \mathrm{L}$, or $\mathrm{TSH}>19.99 \mathrm{mIU} / \mathrm{L})$, and secondary overt hypothyroidism $(\mathrm{TSH}<0.45 \mathrm{mIU} / \mathrm{L}$ with FT4<10.3pmol/L). SHyper was further categorized as mildly decreased TSH (TSH $0.10-0.44 \mathrm{mIU} / \mathrm{L}$ ) or suppressed TSH $(\mathrm{TSH}<0.10 \mathrm{mIU} / \mathrm{L})$.

This article is protected by copyright. All rights reserved. 


\section{Cognitive assessment}

Our primary outcome was incident adjudicated dementia. Change in 3MS over time was our secondary outcome.

Dementia was adjudicated by an expert committee composed of a same panel of experienced medical doctors during the whole follow-up period. This committee identified dementia diagnosis on medical records using a predefined adjudication form. Dementia was defined by any of the following criteria: 1) $\geq 1.5$ standard deviation (SD) race-stratified 3MS decline from Year 1 visit to last available examination; 2) dementia as primary or secondary diagnosis of admission on hospital records with $3 \mathrm{MS} \leq 90$ points at Year 3 or either follow-up (participants were asked about hospital admissions twice a year); 3) prescription of dementia drug (donepezil, galantamine, memantine, rivastigmine, or tacrine) recorded on the yearly drug inventory. Date of first available record of dementia diagnosis was used to define onset.

The 3MS (score of 0-100 point(s), the higher the better), provides a more complete and more sensitive assessment of global cognitive function than the traditional MMSE. ${ }^{16}$ It evaluates attention, basic language, conceptualization, construction, memory, orientation praxis, and verbal fluency. In the Health $\mathrm{ABC}$ study, it was conducted at Years 1, 3, 5, 8, 10, and 11. Because of high number of missing 3MS at Year 11, we stopped the analysis at Year 10. A few participants had missing 3MS at Year 10, but had 3MS available at Year $11(\mathrm{~N}=55)$; in these cases, we used Year 11 3MS for Year 10.

\section{Definition of baseline characteristics and other potential confounders}

Baseline demographic and social characteristics included age, sex, race (white or black), and education (less than high school, high school graduate and some college, college graduate). Literacy was included at Year 3, based on the Rapid Estimate of Adult Literacy in Medicine (REALM). ${ }^{17}$

This article is protected by copyright. All rights reserved. 
Baseline health characteristics included body mass index (BMI; measured as weight in kilograms divided by height in squared meters), smoking history (current, past, or never smokers), drinking history $(<1,1-7$ or $>7$ drinks/week within the last 12 months), weekly exercise $(<500,500<1500$, or $\geq 1500 \mathrm{kcal} /$ week $)$, and medication. Hypertension was defined by self-report of a diagnosis ("told by a doctor"), use of an antihypertensive drug, or elevated blood pressure measurement (systolic blood pressure $\geq 140 \mathrm{mmHg}$ or diastolic blood pressure $\geq 90 \mathrm{mmHg}$ ). Diabetes was defined by self-report of a diagnosis ("told by a doctor"), use of an antidiabetic drug, fasting plasma glucose $\geq 126 \mathrm{mg} / \mathrm{dL} \quad(7.0 \mathrm{mmol} / \mathrm{L})$, or 2 -hour $75 \mathrm{~g}$ glucose tolerance test $>200 \mathrm{mg} / \mathrm{dL}(11.1 \mathrm{mmol} / \mathrm{L})$, according to the American Diabetes Association criteria in place in 2002, i.e. near the baseline visits of Health ABC. ${ }^{18}$ Depression was defined as $\geq 16$ points on the 20 -item Center for Epidemiologic Studies-Depression Scale. ${ }^{19}$ Biological parameters included fasting total cholesterol, high-density lipoprotein cholesterol, low-density lipoprotein cholesterol, triglycerides, glucose, and creatinine, measured by a calorimetric technique (Johnson \& Johnson Vitros 950 analyzer, New Brunswick, New Jersey).

\section{Statistical analysis}

For this analysis, baseline was defined as first TSH measurement, i.e. Year 2 visit, as previously done in Health ABC. ${ }^{15}$ Participants who died before developing dementia

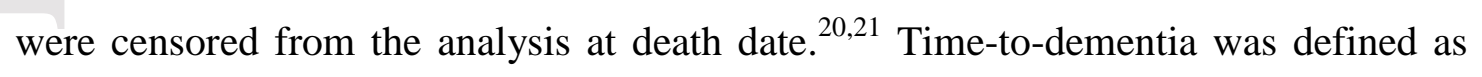
the interval between baseline evaluation of thyroid function and first diagnosis of dementia or censoring from observation at the last available dementia evaluation. For all the analyses, we compared participants with SHyper with mildly decreased or suppressed TSH, and those with SHypo to euthyroids (reference).

We used a multivariable Cox regression model to assess the association between thyroid dysfunction and cause-specific incident dementia, taking into account baseline $3 \mathrm{MS}^{20-22}$ We presented results as hazards ratio (HR) with $95 \%$ confidence interval 
(CI). To generate cumulative incidence graphs, we used a competing-risks regression model, based on Fine and Gray's method, and took into account incidence of death. ${ }^{20-}$ 22

To select the confounding factors, we first chose variables that may be confounding factors, based on previous publications and biological plausibility. The potential confounding factors included age, sex, race, education level, REALM, depression, and study site. We then used a forward stepwise selection using the $P$-values of statistically significant associations in univariable analysis $(P<0.05)$. We adjusted for variables that were statistically significantly associated with both dementia and SCTD. Among them, age, sex, race, and education level were significantly associated with both dementia and SCTD. We therefore adjusted the main analysis for those potential confounding factors. In a second model, we further adjusted for cardiovascular risk factors since they could additionally confound an association between SCTD and dementia. We tested the association of smoking status, alcohol consumption, physical activity, BMI, diabetes mellitus, blood pressure, lipid values, C-reactive protein, fasting glucose, and glycated hemoglobin with both dementia and SCTD. We extended our final statistical models with those cardiovascular risk factors significantly associated with both dementia and SCTD: HDL-cholesterol, C-reactive protein, alcohol consumption, and diastolic blood pressure.

In a secondary analysis, we analyzed 3MS change from baseline to last follow-up. Because of 3MS non-normal distribution, we first calculated the change from baseline in 3MS for each participant, which had a near normal distribution, and then used it to investigate the association between thyroid function and 3MS. We used a repeated measures linear mixed-effects model, with a random intercept for each patient to account for the repeated measurement in different follow-up assessments, and accounting for missing values at follow-up to assess difference in 3MS change according to thyroid function, while controlling for age, sex, race, and education. 
Results were presented as difference in adjusted mean change of $3 \mathrm{MS}$ between euthyroid participants and those with SHyper with mildly decreased or suppressed TSH, or SHypo.

We performed several sensitivity analyses: (i) Excluding participants with thyroxine medication at baseline to assess the risk of endogenous SCTD. (ii) Including only participants with thyroxine medication at baseline to assess the effect of exogenous thyroxine over substitution. (iii) Excluding participants with $3 \mathrm{MS}$ drop $>5$ points between Years 1 and 3, as baseline was defined as Year 2.

To improve statistical efficiency, we finally assessed the relationship of thyroid function with dementia and cognitive decline using fractional polynomials to capture the non-linear association between TSH as a continuous variable and dementia or cognitive decline, adjusting for the same potential confounding factors as in the main analysis. Finally, we tested these associations using log-transformed TSH as a continuous variable.

For all analyses, we assessed effect modification by sex, race, education, and depression. If there was consistent evidence for effect modification $(P<0.05)$, we presented the results stratified by the levels of the effect modifier. We found no significant interaction, except by sex but only in the association between dementia and SHyper with mildly decreased TSH $(P=0.04)$, and not between dementia and SHyper with suppressed TSH, SHypo or TSH as a continuous variable $(P=0.46, P=0.34$ and $P=0.14$, respectively). Because of lack of consistent interaction by sex, we didn't provide stratified analyses by sex. All tests were two-sided, at a 0.05 level of significance. All analyses were done with STATA release 13.1 (StataCorp LP, College Station, Texas).

This article is protected by copyright. All rights reserved. 


\section{RESULTS}

\section{Baseline characteristics}

Mean (SD) age of the participants was 75.1 (2.8) years, with 51.8\% women. Mean (SD) TSH was 2.64 (2.13) mIU/L. At baseline, 22 (0.9\%) participants had SHyper with suppressed TSH, 58 (2.3\%) had SHyper with mildly decreased TSH, 315 (12.3\%) had SHypo, and 253 (9.9\%) were on thyroxine medication. Table 1 presents baseline characteristics of participants according to thyroid function. Participants with SHyper with mildly decreased TSH were older and more likely to be women.

\section{Subclinical thyroid dysfunction and risk of dementia}

During 22457 person-years of follow-up (median 9 years), 574 (22.4\%) participants developed dementia; 493 (85.9\%) were euthyroid, 7 (1.2\%) had SHyper with suppressed TSH, 13 (2.3\%) had SHyper with mildly decreased TSH, and 61 (10.6\%) had SHypo. Figure 1 shows the cumulative incidence of dementia according to thyroid function. The risk of dementia was higher in SHyper with suppressed TSH (adjusted $\mathrm{HR}=2.38,95 \% \mathrm{CI}=1.13 ; 5.04)$, but not in SHyper with mildly decreased TSH (adjusted $\mathrm{HR}=0.79,95 \% \mathrm{CI}=0.45 ; 1.38$, Table 2). SHypo was not associated with dementia (adjusted $\mathrm{HR}=0.91,95 \% \mathrm{CI}=0.70 ; 1.19$, Table 2 ). We found no significant association of TSH with dementia in the continuous analysis using fractional polynomials $(P=0.10$, Appendix Figure 1$)$ or using log-transformed TSH $(P=0.19$, Appendix Figure 2).

Results of the Cox regression were unchanged after further adjusting for cardiovascular risk factors (Table 2). Results were similar in the sensitivity analysis excluding participants with thyroxine medication at baseline (Table 2).

In the sensitivity analysis restricted to participants with thyroxine medication at baseline ( $\mathrm{N}=253)$, the adjusted HR for dementia in SHyper with suppressed TSH was $1.66,95 \% \mathrm{CI}=0.50 ; 5.53$, and $\mathrm{HR}=1.98,95 \% \mathrm{CI}=0.58 ; 6.75$ after further adjustment for cardiovascular risk factors. The sensitivity analysis that excluded 645 participants with This article is protected by copyright. All rights reserved. 
3MS drop >5 points between Years 1 and 3 yielded similar results, with an adjusted HR for dementia of 2.71 (95\%CI 1.20; 6.10) for SHyper with suppressed TSH.

\section{Subclinical thyroid dysfunction and change in 3MS}

During the 10-year follow-up period, participants with SHyper with suppressed TSH had a larger decline in 3MS (adjusted 3MS mean change $-3.89,95 \% \mathrm{CI}=-7.62 ;-0.15$ ) than euthyroid participants (Table 3 and Figure 2). Conversely, we found no significant difference in adjusted mean 3MS change for participants with SHyper with mildly decreased TSH, or SHypo (Table 3 and Figure 2). After further adjustment for cardiovascular risk factors, our results remained unchanged (Table 3). In the sensitivity analysis that excluded participants on thyroxine medication at baseline, point estimates were similar, but no longer statistically significant (Table 3). In the sensitivity analysis that excluded 645 participants with $3 \mathrm{MS}$ drop $>5$ points between Years 1 and 3, adjusted 3MS mean change was -3.07 (95\%CI=-6.40;0.25) for SHyper with suppressed TSH. Adjusted 3MS mean change was not associated with TSH as a continuous variable either in the fractional polynomials analysis $(P=0.17$, Appendix Figure 3 ) or as a log-transformed variable ( $P=0.21$, Appendix Figure 4$)$.

\section{DISCUSSION}

In this prospective cohort of older community-dwelling adults, we found SHyper with suppressed TSH was associated with a higher risk of dementia and a larger decrease in cognition, while SHyper with mildly decreased TSH or SHypo were not. All results were similar after adjusting for cardiovascular risk factors.

Previous retrospective or cross-sectional studies showed an association of SHyper with dementia or cognitive impairment. ${ }^{7-9}$ Although the association between SHyper and dementia was not significant in individual prospective studies, a recent meta-analysis of those studies found a HR for dementia of 1.67 (95\%CI=1.04;2.69) in SHyper. ${ }^{10}$ Interestingly, we found that only SHyper with suppressed TSH was associated with dementia, while SHyper with mildly decreased TSH was not. These results suggest This article is protected by copyright. All rights reserved. 
that there may be a threshold above which higher thyroid function increases the risk of dementia. However, we cannot exclude power insufficiency as an explanation for the lack of association between SHyper with mildly decreased TSH and dementia, because of the relatively small number of participants with SHyper.

Compared to euthyroids, participants with SHyper with suppressed TSH had a larger decrease in 3MS. Previous prospective data are scarce. The MRC Cognitive Function and Ageing Study found a larger MMSE decrease with high normal FT4. ${ }^{23}$ Conversely, in the recent meta-analysis of prospective studies, both SHyper and SHypo were not associated with faster decline in MMSE. ${ }^{10}$ The differences in results might be explained by a relative short follow-up time in previous studies (33 months), and the modest sensitivity of MMSE compared to $3 \mathrm{MS} .{ }^{16}$ Furthermore, it may be due to the degree of SHyper, which was not assessed in previous studies, as in our study 3MS decline was not larger in participants with SHyper mildly decreased TSH. We found no previous study using 3MS.

Several pathophysiological pathways could explain the relationship between hyperthyroid dysfunction and dementia. First, dementia may be caused by an increase in neuronal necrosis ${ }^{24}$ and oxidative stress associated with both hyperthyroidism ${ }^{25}$ and Alzheimer disease. ${ }^{26}$ Second, a genetic susceptibility may exist, as some thyroid hormones target genes are involved in neurogenesis. ${ }^{27}$ Third, dementia could be caused by lower choline in the brain, as described in Alzheimer disease. ${ }^{28}$ In a pilot study, choline/creatine ratio in the brain was indeed lower in patients with untreated Graves' disease, but normalized after treatment. ${ }^{29}$ We hypothesize that the relationship between SHyper and cognitive function may run along similar paths.

Two previous studies assessed the association between TSH as a continuous variable and the risk of dementia: the Rotterdam $\operatorname{Study}^{30}$ found a significantly lower risk of dementia with higher TSH levels in both the full range and the reference range (HR $0.90,95 \% \mathrm{CI}=0.83 ; 0.98$ and $\mathrm{HR} 0.76,95 \% \mathrm{CI}=0.64 ; 0.91$, respectively). Similarly, the 
Cardiovascular Heart Study ${ }^{31}$ found a lower risk of dementia with higher TSH levels within the reference range (HR 0.87, 95\% CI 0.76;1.00, $P=0.05$ ). Both studies found a similar higher risk of dementia with higher FT4 levels (HR 1.04, 95\%CI=1.01;1.07 and $1.04,95 \% \mathrm{CI}=0.97 ; 1.10$ per pmol/L increase in FT4 in the Rotterdam Study and in the Cardiovascular Heart Study, respectively), although the association was not significant in the Cardiovascular Heart Study, except when comparing only quartiles 1 and 4 (difference of -9.6 per 1000 person years, 95\%CI=-17.9;-1.2), or when excluding participants with positive antithyroid peroxidase antibodies (HR 0.84, $95 \% \mathrm{CI}=0.72 ; 0.98, P=0.02)$. Although we found no significant association between TSH and dementia in our continuous analyses, the trend for a higher risk of dementia with lower TSH levels and the significantly increased risk of dementia in participants with SHyper with suppressed TSH are consistent with those previous studies.

We found no significant association of SHypo with either dementia or cognitive decline. This is consistent with the results of two previous meta-analyses ${ }^{10,32}$ and of the recent TRUST trial that found no benefit of thyroxine replacement on executive cognitive function as measured by the letter-digit coding test. ${ }^{33}$ Conversely, another meta-analysis found a significant association in participants younger than 75 years only. ${ }^{34}$ These conflicting findings may be related to the older age of our participants. However, the results of this latter meta-analysis should be interpreted in light of some limitations, as it included heterogeneous study designs (both retrospective and prospective studies) and didn't assess dementia as an endpoint, and as the TRUST trial did not find different results according to age. ${ }^{33}$

Our study had some limitations. First, since thyroid function was only measured once as in most prospective cohorts, we may have misclassified participants with transient TSH abnormality, or included participants who developed overt dysfunction over time. Second, because FT4 was only measured if TSH was $<0.1$ or $>7.0 \mathrm{mIU} / \mathrm{L}$, we may have included participants with overt instead of subclinical thyroid dysfunction, 
although overt thyroid dysfunction is uncommon with TSH $0.1-7.0 \mathrm{mIU} / \mathrm{L} .{ }^{35}$ Third, thyroid function was assessed at Year 2, i.e. one year after baseline evaluation of Health ABC; however, we excluded participants with new dementia at Year 2, and conducted a sensitivity analysis excluding participants with 3MS drop >5 points between Years 1 and 3, which yielded similar results. Fourth, we did not assess different types of dementia, or measure thyroid auto-antibodies. Fifth and finally, our results suggested that the association between SCTD and cognitive impairment was not confounded by cardiovascular risk factors only, but a confounding effect could have been masked by dementia types other than vascular.

Our study presents several strengths and novelties in comparison with previous analyses. First, we included an unselected community-dwelling population without dementia at baseline. Second, the prospective design of the study allows a risk assessment and avoids potential bias related to retrospective analyses. Third, the follow-up time was longer than in most previous studies (median 9 years versus 44.4 months in the recent meta-analysis of prospective cohort studies). ${ }^{10}$ Fourth, we assessed a large number of potential confounding factors, including cardiovascular risk factors, and performed stratified analyses to identify potentially relevant interactions. Fifth, we studied both dementia and cognitive decline; while some subjectivity may remain when diagnosing dementia, the $3 \mathrm{MS}$ is an objective, sensitive and validated test to identify cognitive impairment. Sixth, we assessed thyroid function not only using TSH as a continuous variable, but also according to categories of SCTD, which may be clinically more relevant. Finally, unlike in most previous studies, diagnosis of dementia was adjudicated by an expert committee, reducing the risk of misclassification, and was based on several criteria including not only clinical diagnosis, but also the objective 3MS, as well as the prescription of dementia drugs. In conclusion, in this prospective cohort study, we found that SHyper with suppressed TSH was associated with a higher risk of dementia and a larger decrease in cognitive 
performance. SHyper with mildly decreased TSH and SHypo were not associated with dementia or decreased cognitive performance. Further prospective studies with a larger sample size or an individual participant data analysis with information on different types of dementia and with a larger number of participants with SHyper are warranted to confirm our results and ascertain more specific associations.

\section{AUTHORS CONTRIBUTIONS}

Dr Aubert had full access to all the data in the study and is responsible for the integrity of the data and the accuracy of data analysis. Study concept and design: Aubert and Rodondi. Analysis and interpretation of data: Aubert, Da Costa, Feller and Rodondi. Drafting the manuscript: Aubert. Critical revision of the manuscript for important intellectual content: Bauer, Da Costa, Feller, Rieben, Rodondi, Simonsick and Yaffe. Statistical analysis: Da Costa. Study supervision: Rodondi.

\section{REFERENCES}

1. Surks MI, Ortiz E, Daniels GH, et al. Subclinical thyroid disease: scientific review and guidelines for diagnosis and management. Jama. 2004;291(2):228238.

2. Hollowell JG, Staehling NW, Flanders WD, et al. Serum TSH, T(4), and thyroid antibodies in the United States population (1988 to 1994): National Health and Nutrition Examination Survey (NHANES III). The Journal of clinical endocrinology and metabolism. 2002;87(2):489-499.

3. Delitala AP, Pilia MG, Ferreli L, et al. Prevalence of unknown thyroid disorders in a Sardinian cohort. European journal of endocrinology / European Federation of Endocrine Societies. 2014;171(1):143-149.

4. Adelman S, Blanchard M, Rait G, et al. Prevalence of dementia in AfricanCaribbean compared with UK-born White older people: two-stage crossThis article is protected by copyright. All rights reserved. 
sectional study. The British journal of psychiatry : the journal of mental science. 2011;199(2):119-125.

5. Dugbartey AT. Neurocognitive aspects of hypothyroidism. Archives of internal medicine. 1998;158(13):1413-1418.

6. Whybrow PC, Prange AJ, Jr., Treadway CR. Mental changes accompanying thyroid gland dysfunction. A reappraisal using objective psychological measurement. Archives of general psychiatry. 1969;20(1):48-63.

7. Vadiveloo T, Donnan PT, Cochrane L, et al. The Thyroid Epidemiology, Audit, and Research Study (TEARS): morbidity in patients with endogenous subclinical hyperthyroidism. The Journal of clinical endocrinology and metabolism. 2011;96(5):1344-1351.

8. Ceresini G, Lauretani F, Maggio M, et al. Thyroid function abnormalities and cognitive impairment in elderly people: results of the Invecchiare in Chianti study. Journal of the American Geriatrics Society. 2009;57(1):89-93.

9. Bensenor IM, Lotufo PA, Menezes PR, et al. Subclinical hyperthyroidism and dementia: the Sao Paulo Ageing \& Health Study (SPAH). BMC public health. 2010;10:298.

10. Rieben C, Segna D, da Costa BR, et al. Subclinical Thyroid Dysfunction and the Risk of Cognitive Decline: a Meta-Analysis of Prospective Cohort Studies. The Journal of clinical endocrinology and metabolism. 2016:jc20162129.

11. Egger M, Davey Smith G, Altman D. Systematic Reviews in Health Care: Meta-analysis in Context. London, England: BMJ Publishing Group; 2001.

12. Rodondi N, den Elzen WP, Bauer DC, et al. Subclinical hypothyroidism and the risk of coronary heart disease and mortality. Jama. 2010;304(12):13651374.

13. Zeki Al Hazzouri A, Yaffe K. Arterial stiffness and cognitive function in the elderly. Journal of Alzheimer's disease : JAD. 2014;42 Suppl 4:S503-514.

This article is protected by copyright. All rights reserved. 
14. von Elm E, Altman DG, Egger M, et al. The Strengthening the Reporting of Observational Studies in Epidemiology (STROBE) statement: guidelines for reporting observational studies. Annals of internal medicine. 2007;147(8):573577.

15. Rodondi N, Newman AB, Vittinghoff E, et al. Subclinical hypothyroidism and the risk of heart failure, other cardiovascular events, and death. Archives of internal medicine. 2005;165(21):2460-2466.

16. Teng EL, Chui HC. The Modified Mini-Mental State (3MS) examination. The Journal of clinical psychiatry. 1987;48(8):314-318.

17. Davis TC, Long SW, Jackson RH, et al. Rapid estimate of adult literacy in medicine: a shortened screening instrument. Family medicine. 1993;25(6):391395.

18. Yaffe K, Falvey CM, Hamilton N, et al. Association between hypoglycemia and dementia in a biracial cohort of older adults with diabetes mellitus. JAMA internal medicine. 2013;173(14):1300-1306.

19. Radloff L. The CES-D scale: A self-report depression scale for research in the general population. Appl Psychol Meas 1977;1:385- 401

20. Andersen PK, Geskus RB, de Witte T, et al. Competing risks in epidemiology: possibilities and pitfalls. International journal of epidemiology. 2012;41(3):861-870.

21. Hinchliffe SR, Lambert PC. Flexible parametric modelling of cause-specific hazards to estimate cumulative incidence functions. BMC medical research methodology. 2013;13:13.

22. Fine JPG, R.J. A Proportional Hazards Model for the Subdistribution of a Competing Risk Journal of the American Statistical Association 1999;94(46):496-509.

This article is protected by copyright. All rights reserved. 
23. Hogervorst E, Huppert F, Matthews FE, et al. Thyroid function and cognitive decline in the MRC Cognitive Function and Ageing Study. Psychoneuroendocrinology. 2008;33(7):1013-1022.

24. Chan RS, Huey ED, Maecker HL, et al. Endocrine modulators of necrotic neuron death. Brain pathology (Zurich, Switzerland). 1996;6(4):481-491.

25. Aslan M, Cosar N, Celik H, et al. Evaluation of oxidative status in patients with hyperthyroidism. Endocrine. 2011;40(2):285-289.

26. Fu AL, Dong ZH, Sun MJ. Protective effect of N-acetyl-L-cysteine on amyloid beta-peptide-induced learning and memory deficits in mice. Brain research. 2006;1109(1):201-206.

27. Kapoor R, Fanibunda SE, Desouza LA, et al. Perspectives on thyroid hormone action in adult neurogenesis. Journal of neurochemistry. 2015;133(5):599-616.

28. Coyle JT, Price DL, DeLong MR. Alzheimer's disease: a disorder of cortical cholinergic innervation. Science (New York, NY). 1983;219(4589):1184-1190.

29. Bhatara VS, Tripathi RP, Sankar R, et al. Frontal lobe proton magneticresonance spectroscopy in Graves' disease: a pilot study. Psychoneuroendocrinology. 1998;23(6):605-612.

30. Chaker L, Wolters FJ, Bos D, et al. Thyroid function and the risk of dementia: The Rotterdam Study. Neurology. 2016;87(16):1688-1695.

31. Cappola AR, Arnold AM, Wulczyn K, et al. Thyroid function in the euthyroid range and adverse outcomes in older adults. The Journal of clinical endocrinology and metabolism. 2015;100(3):1088-1096.

32. Akintola AA, Jansen SW, van Bodegom D, et al. Subclinical hypothyroidism and cognitive function in people over 60 years: a systematic review and metaanalysis. Frontiers in aging neuroscience. 2015;7:150.

This article is protected by copyright. All rights reserved. 
33. Stott DJ, Rodondi N, Kearney PM, et al. Thyroid Hormone Therapy for Older Adults with Subclinical Hypothyroidism. The New England journal of medicine. 2017.

34. Pasqualetti G, Pagano G, Rengo G, et al. Subclinical Hypothyroidism and Cognitive Impairment: Systematic Review and Meta-Analysis. The Journal of clinical endocrinology and metabolism. 2015;100(11):4240-4248.

35. Bauer DC, Brown AN. Sensitive thyrotropin and free thyroxine testing in outpatients. Are both necessary? Archives of internal medicine. 1996;156(20):2333-2337.

This article is protected by copyright. All rights reserved. 
Table 1. Baseline characteristics of the whole cohort, and according to thyroid function

\begin{tabular}{|c|c|c|c|c|c|c|c|c|}
\hline Characteristics & $\begin{array}{c}\text { Total } \\
(\mathbf{N}=\mathbf{2 5 5 8})\end{array}$ & $\begin{array}{l}\text { Euthyroidis } \\
\text { m }(\mathbf{N}=\mathbf{2 1 6 3})\end{array}$ & $\begin{array}{c}\text { SHypo } \\
(\mathbf{N}=\mathbf{3 1 5})\end{array}$ & $P$-value ${ }^{a}$ & $\begin{array}{c}\text { SHyper with } \\
\text { TSH 0.10- } \\
\text { 0.44mIU/L } \\
(\mathrm{N}=58)\end{array}$ & $P$-value ${ }^{b}$ & $\begin{array}{c}\text { SHyper with } \\
\text { TSH } \\
<0.10 \mathrm{mIU} / \mathrm{L} \\
(\mathrm{N}=22) \\
\end{array}$ & $P$-value \\
\hline \multicolumn{9}{|l|}{ Socio-demographics } \\
\hline Age, years & $75.1(2.8)$ & $75.1(2.9)$ & $75.3(2.7)$ & 0.34 & $75.9(3.0)$ & 0.04 & $75.8(3.2)$ & 0.28 \\
\hline Women & $1326(51.8)$ & $1095(50.7)$ & $175(55.6)$ & 0.10 & $42(72.4)$ & 0.001 & $14(63.6)$ & 0.23 \\
\hline Race, White & $1567(61.3)$ & $1284(59.4)$ & $236(74.9)$ & $<0.0001$ & $34(58.6)$ & 0.91 & $13(59.1)$ & 0.98 \\
\hline Site, Memphis & $1286(50.3)$ & $1082(50.0)$ & $160(50.8)$ & 0.80 & $31(53.5)$ & 0.61 & $13(59.1)$ & 0.40 \\
\hline Education level & & & & $0.003^{\mathrm{c}}$ & & $0.48^{c}$ & & $0.57^{\mathrm{c}}$ \\
\hline$<$ High school graduate & $592(23.2)$ & $523(24.3)$ & $49(15.6)$ & & $13(22.4)$ & & $7(31.8)$ & \\
\hline High school graduate & $833(32.7)$ & $694(32.2)$ & $111(35.2)$ & & $23(39.7)$ & & $5(22.7)$ & \\
\hline College graduate & $1126(44.1)$ & $939(43.6)$ & $155(49.2)$ & & $22(37.9)$ & & $10(45.5)$ & \\
\hline REALM $\geq 60(\mathrm{Y} 3)$ & $506(20.9)$ & $433(21.2)$ & $54(17.8)$ & & $12(21.8)$ & 0.92 & $7(33.3)$ & 0.18 \\
\hline Smoking status & & & & $0.20^{\mathrm{c}}$ & & $0.34^{\mathrm{c}}$ & & $0.08^{\mathrm{c}}$ \\
\hline Never & $1143(44.7)$ & $956(44.3)$ & $144(45.7)$ & & $28(48.3)$ & & $15(68.2)$ & \\
\hline Former & $1179(46.1)$ & $1000(46.3)$ & $151(47.9)$ & & $8(13.8)$ & & $1(4.6)$ & \\
\hline Current & $233(9.1)$ & $204(9.4)$ & $20(6.4)$ & & $22(37.9)$ & & $6(27.3)$ & \\
\hline Alcohol, drinks/week & & & & $0.83^{c}$ & & $0.11^{\mathrm{c}}$ & & $0.10^{\mathrm{c}}$ \\
\hline$<1$ & $1796(70.4)$ & $1513(70.1)$ & $215(68.7)$ & & $48(82.8)$ & & $20(90.9)$ & \\
\hline $1-7$ & $567(22.2)$ & $483(22.4)$ & $75(24.0)$ & & $8(13.8)$ & & $1(4.6)$ & \\
\hline$>7$ & $187(7.2)$ & $161(7.5)$ & $23(7.4)$ & & $2(3.5)$ & & $1(4.6)$ & \\
\hline $3 \mathrm{MS}$ at Year $1^{\mathrm{e}}$ & $90.6(7.9)$ & $90.4(8.1)$ & $91.7(7.1)$ & 0.01 & $92.0(6.8)$ & 0.15 & $91.0(8.4)$ & 0.72 \\
\hline Depression at Year $1^{\mathrm{f}}$ & $113(4.5)$ & $96(4.5)$ & $13(4.1)$ & 0.99 & $1(1.7)$ & 0.42 & $1(4.6)$ & 0.84 \\
\hline Physical activity, kcal/week & & & & $0.02^{\mathrm{c}}$ & & $0.40^{\mathrm{c}}$ & & \\
\hline $\begin{array}{l}<500 \\
500-<1500\end{array}$ & $\begin{array}{c}1293(50.6) \\
714(27.9)\end{array}$ & $\begin{array}{c}1112(51.4) \\
595(27.5)\end{array}$ & $\begin{array}{c}137(43.5) \\
95(30.2)\end{array}$ & & $\begin{array}{c}33(856.9) \\
17(29.3)\end{array}$ & & $\begin{array}{c}11(50.0) \\
7(31.8)\end{array}$ & \\
\hline
\end{tabular}

This article is protected by copyright. All rights reserved. 


\begin{tabular}{|c|c|c|c|c|c|c|c|c|}
\hline$\geq 1500$ & $551(21.5)$ & $456(21.1)$ & $83(26.4)$ & & $8(13.8)$ & & $4(18.2)$ & \\
\hline Hypertension & $1822(71.2)$ & $1566(72.4)$ & $199(63.7)$ & 0.001 & $41(70.7)$ & 0.77 & $16(72.7)$ & 0.97 \\
\hline Diabetes mellitus & $468(18.3)$ & $400(18.5)$ & $48(15.2)$ & 0.16 & $14(24.1)$ & 0.28 & $6(27.3)$ & 0.29 \\
\hline Body mass index, $\mathrm{kg} / \mathrm{m}^{2}$ & $27.4(4.8)$ & $27.5(4.9)$ & $26.8(4.5)$ & 0.02 & $26.6(3.9)$ & 0.16 & $26.6(4.1)$ & 0.39 \\
\hline Systolic blood pressure & $135.2(20.7)$ & $135.7(20.7)$ & $133.0(20.6)$ & 0.04 & $132.3(24.2)$ & 0.23 & $133.0(20.6)$ & 0.54 \\
\hline Diastolic blood pressure & $71.1(11.6)$ & $71.4(11.8)$ & $69.7(10.3)$ & 0.01 & $67.8(12.1)$ & 0.02 & $71.7(12.4)$ & 0.92 \\
\hline \multicolumn{9}{|l|}{ Lipoproteins } \\
\hline Total cholesterol, mmol/l & $5.3(1.0)$ & $5.3(1.0)$ & $5.5(1.0)$ & 0.01 & $5.1(0.9)$ & 0.22 & $4.6(0.7)$ & 0.003 \\
\hline HDL-cholesterol, mmol/l & $1.4(0.4)$ & $1.4(0.4)$ & $1.43(0.4)$ & 0.03 & $1.5(0.5)$ & 0.30 & $1.3(0.3)$ & 0.33 \\
\hline LDL-cholesterol, mmol/1 & $3.1(0.9)$ & $3.1(0.9)$ & $3.2(0.9)$ & 0.25 & $3.1(0.8)$ & 0.60 & $2.8(0.7)$ & 0.06 \\
\hline Triglycerides, $\mathrm{mmol} / \mathrm{l}$ & $1.6(0.9)$ & $1.6(0.9)$ & $1.7(1.0)$ & 0.01 & $1.5(0.8)$ & 0.74 & $1.6(1.5)$ & 0.66 \\
\hline
\end{tabular}

Abbreviations: FT4, free thyroxine; HDL, high-density lipoprotein; LDL, low-density lipoprotein; 3MS, Modified Mini-Mental State; N, number; REALM, Rapid Estimate of Adult Literacy in Medicine; SD, standard deviation; SHyper, subclinical hyperthyroidism; SHypo, subclinical hypothyroidism.

There were seven participants with missing data for education level, 139 for REALM, three for smoking status, eight for alcohol consumption, 19 for depression, 119 for total cholesterol, 113 for LDL-cholesterol, and 82 for HDL-cholesterol. Values are mean (SD) or $\mathrm{n}(\%)$. For some covariates, there were missing values that were excluded.

${ }^{a} P$-value for the difference between euthyroidism and SHypo.

${ }^{\mathrm{b}} P$-value for the difference between euthyroidism and SHyper with mildly decreased TSH $(0.10-0.44 \mathrm{mIU} / \mathrm{L})$.

${ }^{\mathrm{c}} P$-value for the difference between euthyroidism and SHyper with suppressed TSH $(<0.10 \mathrm{mIU} / \mathrm{L})$.

${ }^{\mathrm{d}} P$-value over groups.

${ }^{\mathrm{e}}$ The $3 \mathrm{MS}$ ranges from 0 to a best score of 100 points.

${ }^{\mathrm{f}}$ Depression was defined as a score $\geq 16$ on the 20 -item Center for Epidemiologic Studies-Depression Scale (CES-D).

This article is protected by copyright. All rights reserved. 
Table 2. Adjusted hazard ratios for the risk of dementia in subclinical hyperthyroidism with suppressed

TSH, subclinical hyperthyroidism with mildly decreased TSH and subclinical hypothyroidism, compared with euthyroidism.

\begin{tabular}{|c|c|c|c|}
\hline & $\begin{array}{l}\text { N dementia/ } \mathbf{N} \text { total in } \\
\text { participants with } \\
\text { subclinical thyroid } \\
\text { dysfunction }\end{array}$ & $\begin{array}{l}\text { N dementia/ } \\
\mathbf{N} \text { total in } \\
\text { euthyroid } \\
\text { participants }\end{array}$ & HR $(95 \% \mathrm{CI})$ \\
\hline \multicolumn{4}{|l|}{ Subclinical hyperthyroidism } \\
\hline $\begin{array}{l}\text { Main analysis }^{\mathrm{a}} \\
\text { Suppressed TSH }^{\mathrm{b}} \\
\text { Mildly decreased TSH }^{\mathrm{c}}\end{array}$ & $\begin{array}{c}7 / 22 \\
13 / 58\end{array}$ & $\begin{array}{l}230 / 1066 \\
261 / 1090\end{array}$ & $\begin{array}{l}2.38(1.13 ; 5.04) \\
0.79(0.45 ; 1.38)\end{array}$ \\
\hline $\begin{array}{l}\text { Adjusting for cardiovascular risk factors } \\
\text { Suppressed }^{\mathrm{d}, \mathrm{e}} \\
\text { Mildly decreased }^{\mathrm{b}} \mathrm{TSH}^{\mathrm{c}}\end{array}$ & $\begin{array}{c}7 / 22 \\
13 / 55\end{array}$ & $\begin{array}{l}224 / 1026 \\
248 / 1049\end{array}$ & $\begin{array}{l}2.41(1.14 ; 5.10) \\
0.80(0.46 ; 1.39)\end{array}$ \\
\hline $\begin{array}{l}\text { Excluding participants with thyroxine } \\
\text { medication at baseline } \\
\text { Suppressed TSH }^{\mathrm{b}} \\
{\text { Mildly decreased } \mathrm{TSH}^{\mathrm{c}}}^{\mathrm{c}}\end{array}$ & $\begin{array}{l}5 / 14 \\
5 / 28\end{array}$ & $\begin{array}{c}218 / 1024 \\
228 / 960\end{array}$ & $\begin{array}{l}3.03(1.13 ; 8.15) \\
0.82(0.37 ; 1.85)\end{array}$ \\
\hline \multicolumn{4}{|l|}{ Subclinical hypothyroidism } \\
\hline Main analysis ${ }^{\mathrm{a}}$ & $61 / 315$ & $491 / 2156$ & $0.91(0.70 ; 1.19)$ \\
\hline Adjusting for cardiovascular risk factors ${ }^{\mathrm{d}, \mathrm{e}}$ & $59 / 309$ & $472 / 2075$ & $0.89(0.68 ; 1.17)$ \\
\hline $\begin{array}{l}\text { Excluding participants with thyroxine } \\
\text { medication at baseline } \mathrm{f}\end{array}$ & $53 / 267$ & $456 / 1984$ & $0.96(0.72 ; 1.27)$ \\
\hline
\end{tabular}

Abbreviations: CI, confidence interval; 3MS, Modified Mini-Mental State; N, number; HR, hazard ratio.

${ }^{a}$ The main analysis was adjusted for age, sex, race, education level and 3MS at baseline. There were 7 missing values for education level, all in participants with euthyroidism (2 participants with dementia, 5 participants without dementia).

${ }^{\mathrm{b}}$ Suppressed TSH was defined as TSH $<0.10 \mathrm{mIU} / \mathrm{L}$.

${ }^{\mathrm{c}}$ Mildly decreased TSH was defined as TSH 0.10-0.44mIU/L.

${ }^{\mathrm{d}}$ Further adjustment for cardiovascular risk factors that were associated with subclinical thyroid dysfunction and dementia: high density lipoprotein cholesterol (HDL-cholesterol), C-reactive protein, alcohol consumption and diastolic blood pressure.

${ }^{\mathrm{e}}$ Number of missing values for cardiovascular risk factors in the study population: $\mathrm{n}=82$ for HDL-cholesterol, 21 for C-reactive protein, $\mathrm{n}=8$ for alcohol consumption, $\mathrm{n}=0$ for diastolic blood pressure.

253/2558 (9.9\%) participants had thyroxine medication at baseline.

This article is protected by copyright. All rights reserved. 
Table 3. Difference in adjusted mean change from baseline over all time

points for 3MS, in subclinical hyperthyroidism with suppressed TSH,

subclinical hyperthyroidism with mildly decreased TSH and subclinical hypothyroidism, compared with euthyroidism.

\begin{tabular}{|c|c|}
\hline & $\begin{array}{l}\text { Difference in adjusted mean change } \\
(95 \% \mathrm{CI})\end{array}$ \\
\hline \multicolumn{2}{|l|}{ Main analysis $^{\mathrm{a}}$} \\
\hline \multicolumn{2}{|l|}{ Subclinical hyperthyroidism } \\
\hline Suppressed TSH ${ }^{\mathrm{b}}$ & $-3.89(-7.62 ;-0.15)$ \\
\hline Mildly decreased $\mathrm{TSH}^{\mathrm{c}}$ & $-0.24(-2.34 ; 1.85)$ \\
\hline Subclinical hypothyroidism & $-0.01(-0.98 ; 0.95)$ \\
\hline \multicolumn{2}{|c|}{ Adjusting for cardiovascular risk factors ${ }^{\mathrm{d}, \mathrm{e}}$} \\
\hline \multicolumn{2}{|l|}{ Subclinical h } \\
\hline Suppressed TSH ${ }^{\mathrm{b}}$ & $-3.86(-7.60 ;-0.13)$ \\
\hline Mildly decreased TSH ${ }^{\mathrm{c}}$ & $-0.27(-2.40 ; 1.86)$ \\
\hline Subclinical hypothyroidism & $0.18(-0.80 ; 1.15)$ \\
\hline \multicolumn{2}{|c|}{ Excluding participants with thyroxine medication at baseline ${ }^{\mathrm{f}}$} \\
\hline \multicolumn{2}{|l|}{ Subclinical hyperthyroidism } \\
\hline Suppressed TSH ${ }^{\mathrm{b}}$ & $-3.33(-8.36 ; 1.70)$ \\
\hline Mildly decreased $\mathrm{TSH}^{\mathrm{c}}$ & $-1.30(-4.27 ; 1.68)$ \\
\hline Subclinical hypothyroidism & $-0.14(-1.18 ; 0.90)$ \\
\hline
\end{tabular}

Abbreviations: CI, confidence interval; HR, hazard ratio; 3MS, Modified Mini-Mental State; N, number; TSH, thyroid-stimulating hormone.

${ }^{a}$ The main analysis was adjusted for age, sex, race, and education level. There were 7 missing values for education level, all in participants with euthyroidism ( 2 participants with dementia, 5 participants without dementia).

${ }^{\mathrm{b}}$ Suppressed TSH was defined as TSH $<0.10 \mathrm{mIU} / \mathrm{L}$.

${ }^{c}$ Mildly decreased TSH was defined as TSH $0.10-0.44 \mathrm{mIU} / \mathrm{L}$.

${ }^{\mathrm{d}}$ Further adjustment for cardiovascular risk factors that were associated with subclinical thyroid dysfunction and dementia: high density lipoprotein cholesterol (HDL-cholesterol), C-reactive protein, alcohol consumption and diastolic blood pressure.

${ }^{\mathrm{e}}$ Number of missing values for cardiovascular risk factors in the study population: $\mathrm{n}=82$ for HDL-cholesterol, 21 for C-reactive protein, $n=8$ for alcohol consumption, $n=0$ for diastolic blood pressure.

f $253 / 2558(9.9 \%)$ participants had thyroxine medication at baseline.

This article is protected by copyright. All rights reserved. 


\section{FIGURES CAPTIONS}

\section{Figure 1.}

Title: Cumulative adjusted incidence of dementia in subclinical thyroid dysfunction compared with euthyroidism.

Legend: A) subclinical hyperthyroidism with suppressed TSH (TSH $<0.10 \mathrm{mIU} / \mathrm{L})$ or with mildly decreased (TSH 0.10-0.44mIU/L) B) subclinical hypothyroidism. Analyses were adjusted for age, sex, race, education level and baseline 3MS.

\section{Figure 2.}

Title: 3MS change from baseline in subclinical thyroid dysfunction compared with euthyroidism.

Legend: A) subclinical hyperthyroidism with suppressed TSH (TSH <0.10mIU/L) or with mildly decreased (TSH 0.10-0.44mIU/L) B) subclinical hypothyroidism. Analyses were adjusted for age, sex, race and education level. Abbreviations: CI, confidence interval; 3MS, Modified Mini-Mental State; SHyper, subclinical hyperthyroidism; SHypo, subclinical hypothyroidism.

This article is protected by copyright. All rights reserved. 


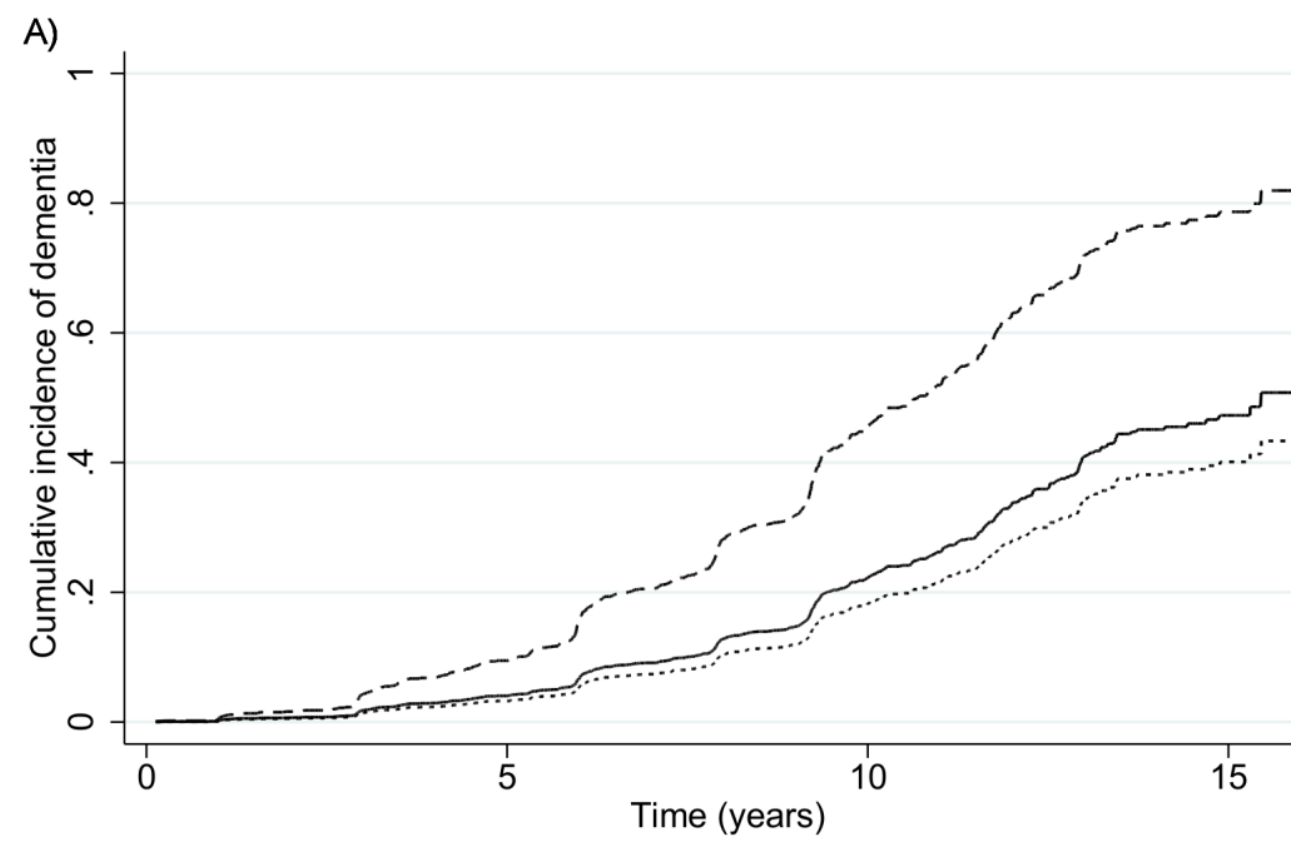

Euthyroidism

TSH $0.10-0.45 \mathrm{mIU} / \mathrm{L}$

$\mathrm{TSH}<0.10 \mathrm{mlU} / \mathrm{L}$

B)

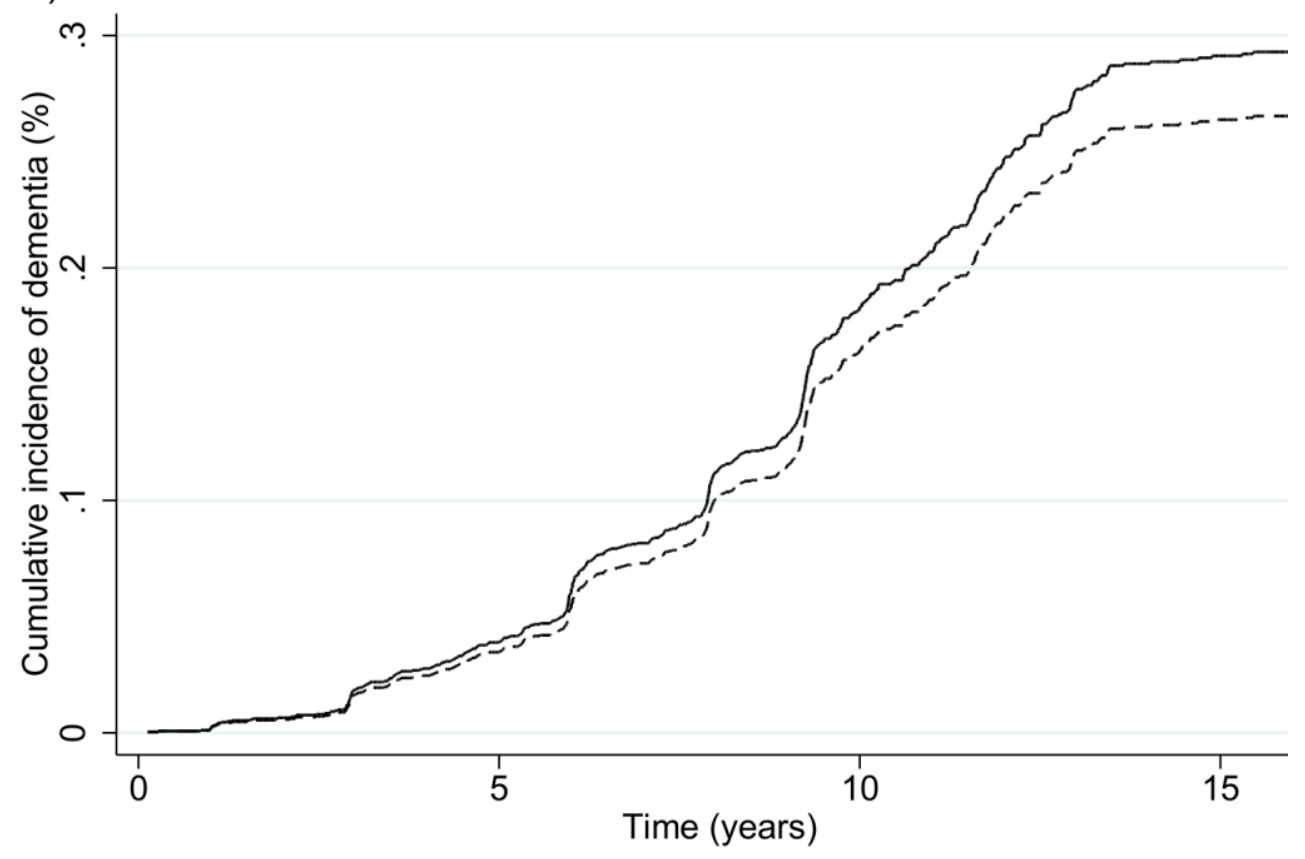

Euthyroidism - - - - Subclinical hypothyroidism

This article is protected by copyright. All rights reserved. 


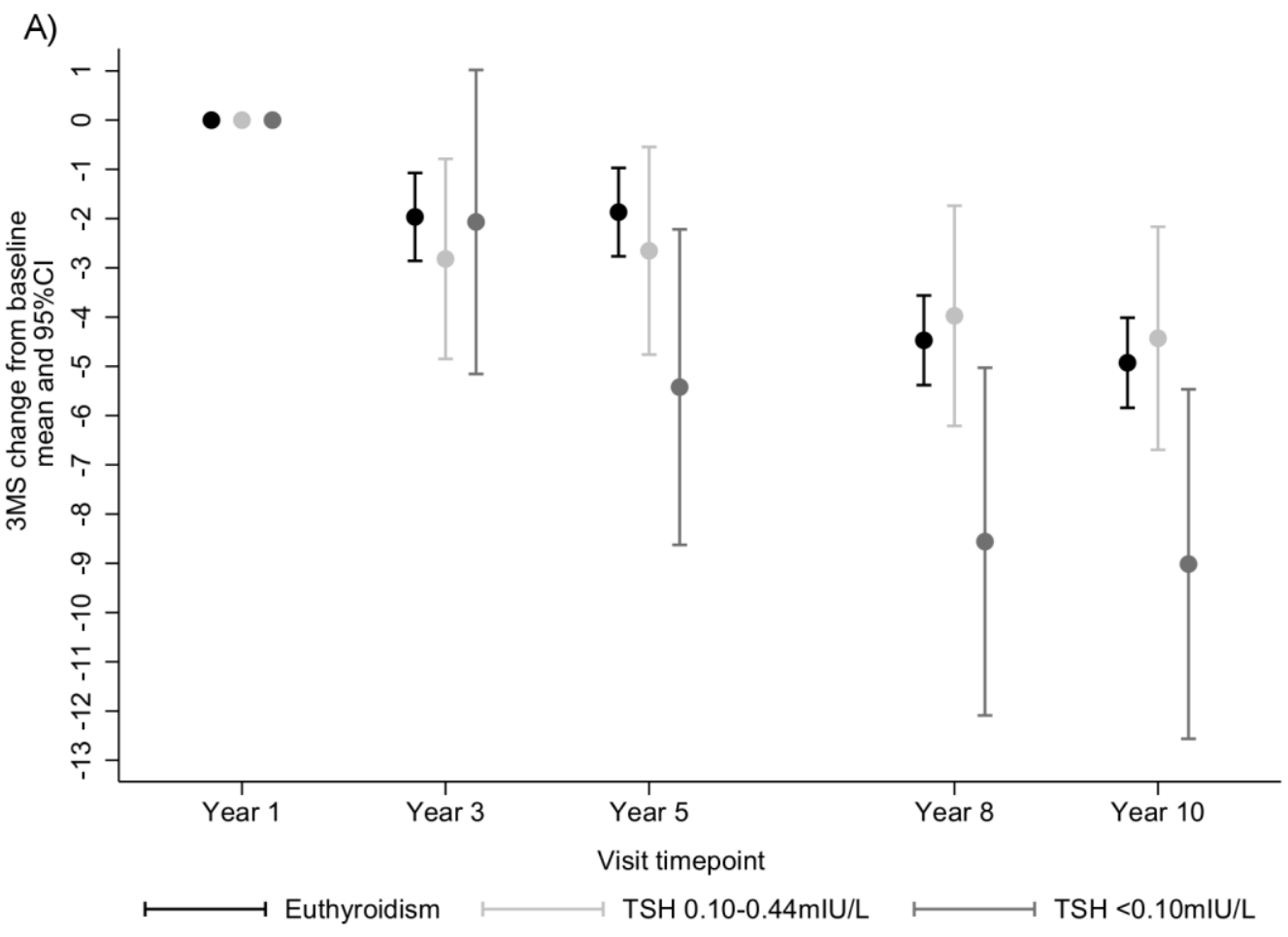

B)

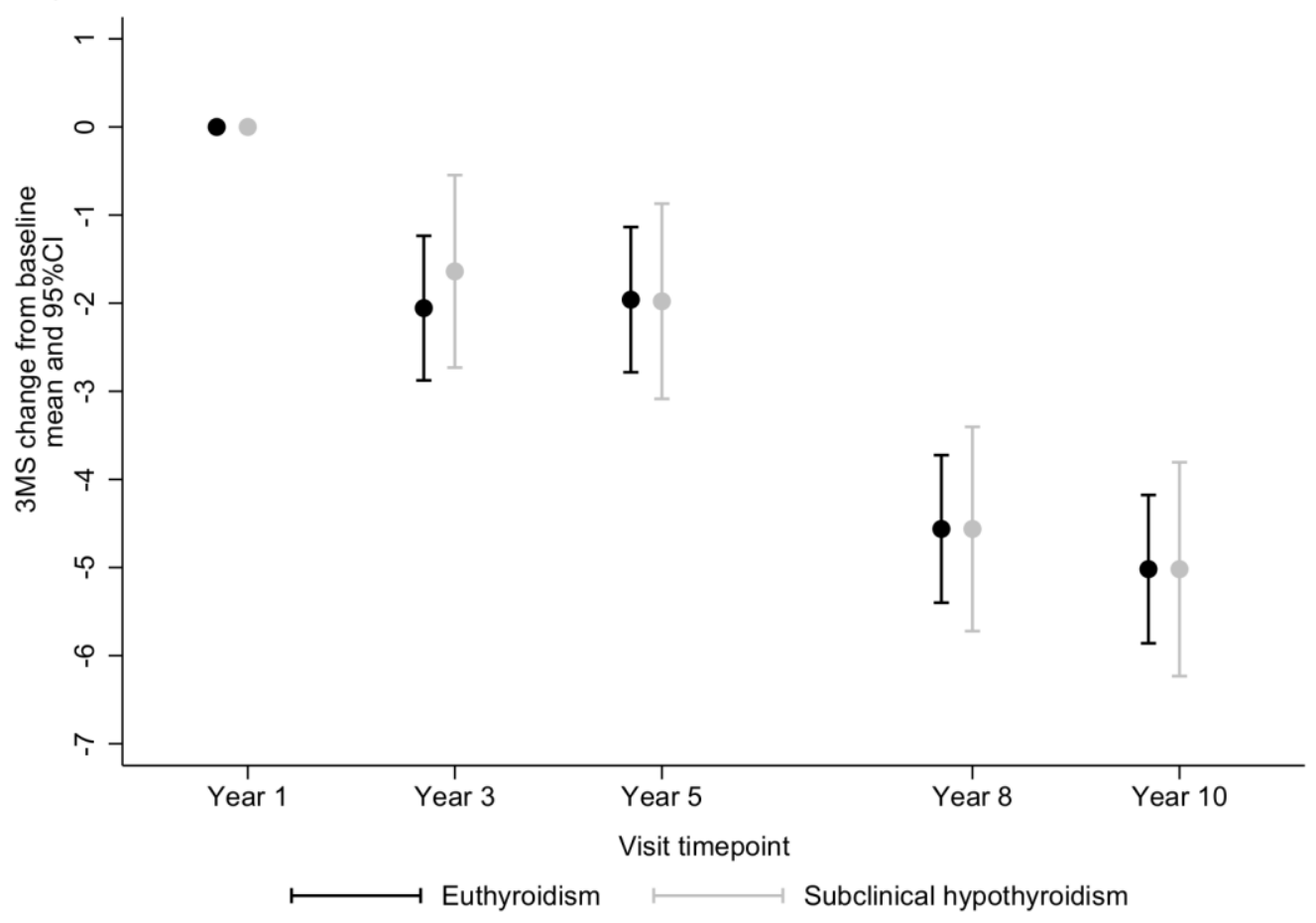

This article is protected by copyright. All rights reserved. 